\title{
Biopolymer-supported iron oxide nanocomposite: Preparation and catalytic application in the synthesis of benzodiazepine derivatives
}

\author{
Ali Maleki*, Maryam Kamalzare \\ Department of Chemistry, Iran University of Science \& Technology, Tehran 16846-13114, Iran \\ E-mail:maleki@iust.ac.ir
}

\begin{abstract}
In this work, cellulose-based nanocomposite containing high contents of $\mathrm{Fe}_{3} \mathrm{O}_{4}$ nanoparticles used as a catalyst in the condensation reaction between o-phenylenediamines and ketones for synthesis of benzodiazepines in good to excellent yields under mild conditions. A good correlation between the amount of surface acid sites as well as the surface morphology of the catalysts and the catalytic activity has been observed. This method has been found to be ecofriendly, simple and economical. The solid supported nanocatalyst could be recycled and reused without significant loss of its catalytic activity.
\end{abstract}

Keywords: Benzodiazepine, nanocomposite, biodegradable polymer, cellulose, nano- $\mathrm{Fe}_{3} \mathrm{O}_{4}$.

\section{Introduction}

Among natural or biopolymers, cellulose is one of the most abundant materials in the world and it has been widely studied in organic transformations [1]. It constitutes the most abundant renewable polymer resource available today. As a chemical raw material, it is generally wellknown that it has been used in the form of fibers or derivatives in recent century for a wide spectrum of products and materials in daily life [2]. Cellulose is potential as a biodegradable 
material, can be used for several applications and also as support for bonding several functional groups which act as catalysts to yield clean efficient and fast chemical reactions [3].

Benzodiazepines constitute an important class of heterocyclic compounds which possess a wide range of therapeutic and pharmacological properties. They are widely used as anticonvulsant, antianxiety, analgesic, sedative, anti-depressive, and hypnotic agents [4]. Owing to their versatile applications various methods for the synthesis of benzodiazepines have been reported. One of the commonly reported methods for the synthesis of benzodiazepines is the condensation reaction between o-phenylenediamines and ketones [5], enones [6] or $\beta$ haloketones [7], using ionic liquids [8], under microwave irradiation [9] and $\mathrm{SbCl}_{3}-\mathrm{Al}_{2} \mathrm{O}_{3}$ [10], $\mathrm{HClO}_{4}$ [11], acetic acid [12], PPA or $\mathrm{SiO}_{2}$ [13], $\mathrm{TiCl}_{4}: \mathrm{Sm}$ [14], $\mathrm{Yb}(\mathrm{OTf})_{3}$ [15], $\mathrm{H}_{14}\left[\mathrm{NaP}_{5} \mathrm{~W}_{30} \mathrm{O}_{110}\right]$ [16]. The reported methods of the synthesis of benzodiazepine suffers from one or other limitations such as harsh reaction conditions, expensive reagents, low yields, relatively long reaction time and formations of side products [17-25]. To find a new methodology for the synthesis of benzodiazepines in terms of simplicity, eco-friendly and economic viability is still of prime importance.

In continuation of our interest in the application of nanocatalysts in organic synthesis [26], in this work, cellulose-based nanocomposite containing high contents of $\mathrm{Fe}_{3} \mathrm{O}_{4}$ nanoparticles used as a catalyst in the condensation reaction between o-phenylenediamines and ketones for synthesis of benzodiazepines in good to excellent yields under mild conditions (Scheme 1).

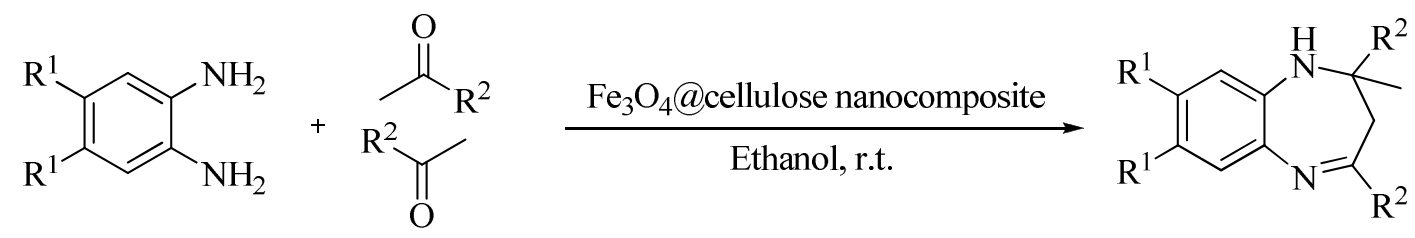

Scheme 1. 


\section{Experimental}

\section{General}

All solvents, chemicals and reagents were purchased from Merck, Fluka and Aldrich chemical companies. Melting points were measured on an Electrothermal 9100 apparatus and are uncorrected. SEM images were obtained on a Seron AIS 2100. EDX spectra were recorded on Numerix DXP-X10P.

\section{Preparation of $\mathrm{Fe}_{3} \mathrm{O}_{4} @$ cellulosenanocomposite}

Cellulose was dissolved directly in the $\mathrm{NaOH}$ aqueous solution, which was precooled to -8 ${ }^{\circ} \mathrm{C}$, to prepare $4 \mathrm{wt} \%$ cellulose solution. The resulting solution was centrifuged at $2000 \mathrm{rpm}$ for $30 \mathrm{~min}$ for degasification. The cellulose solution was cast onto a glass plate to give a thickness of $0.5 \mathrm{~mm}$ and was then immersed in a $2000 \mathrm{~mL} \mathrm{H}_{2} \mathrm{SO}_{4}(5 \mathrm{wt} \%)$ bath for 5 min for the coagulation and regeneration of the cellulose films. The resulting films were washed with running water and subsequently with distilled water. The wet films obtained were immersed in a $500 \mathrm{~mL}$ mixture of aqueous $\mathrm{FeCl}_{3}$ for $24 \mathrm{~h}$; we then washed out the iron ions adsorbed on the surface of the film with distilled water. Then, the films were immersed in $500 \mathrm{~mL}$ of aqueous $\mathrm{NaOH}(4 \mathrm{~mol} / \mathrm{L})$ for $20 \mathrm{~min}$ and were then rinsed with distilled water for several times.

Synthesis of benzodiazepine derivatives

A mixture of $o$-phenylenediamine $(1 \mathrm{mmol})$ and ketone $(2.2 \mathrm{mmol}), 5 \mathrm{~mL}$ of solvent, and $0.02 \mathrm{~g}$ of $\mathrm{Fe}_{3} \mathrm{O}_{4} @$ cellulose catalyst were mixed and stirring in a room temperature for 
appropriate times according to Table 1 . The progress of reaction was monitored by thin layer chromatography ( $n$-hexane/ethyl acetate 3/1). After the completion of the reaction the catalyst was removed and the obtained solid is filtered, washed with ethanol and dry at room temperature for giving melting points.

\section{Results and discussion}

Initially, to optimize the reaction conditions, we studied the reaction of $o$-phenylenediamine (1 mmol), cyclohexanone $(2.2 \mathrm{mmol})$, as a simple model reaction in the presence of different catalytic amount of $\mathrm{Fe}_{3} \mathrm{O}_{4} @$ cellulose at room temperature with ethanol. It was found that $0.02 \mathrm{~g}$ of catalyst was sufficient to catalyze the reaction efficiently to produce high yields in short reaction time. As shown in Table 1, the reaction was not successful in the absence of the catalyst. Using $0.02 \mathrm{~g}$ of the catalyst was sufficient to progress the reaction and an increase of the catalyst amount did not improved the yields.

Table 1. Amount of $\mathrm{Fe}_{3} \mathrm{O}_{4} @$ cellulose nanocatalyst on the model reaction.

\begin{tabular}{|c|c|c|c|c|c|c|}
\hline Entry & Catalyst & $\begin{array}{l}\text { Amount of } \\
\text { catalyst (g) }\end{array}$ & Solvent & Temp. $\left({ }^{\circ} \mathrm{C}\right)$ & Time (min) & Yield $^{\mathrm{a}}(\%)$ \\
\hline 1 & - & - & Ethanol & 25 & 300 & Trace \\
\hline 2 & $\mathrm{Fe}_{3} \mathrm{O}_{4} @$ cellulose & 0.01 & Ethanol & 25 & 60 & 71 \\
\hline 3 & $\mathrm{Fe}_{3} \mathrm{O}_{4} @$ cellulose & 0.02 & Ethanol & 25 & 25 & 96 \\
\hline 4 & $\mathrm{Fe}_{3} \mathrm{O}_{4} @$ cellulose & 0.03 & Ethanol & 25 & 25 & 95 \\
\hline
\end{tabular}

\footnotetext{
${ }^{a}$ Isolated yield.
} 
Then the solvent of the reaction was optimized. It was found that ethanol is appropriate solvent to produce high yields in short reaction time in comparison with other polar, non-polar, protic and aprotic solvents.

After optimization of the reaction conditions, we studied the generality of this method. Using this procedure, different kinds of ketones were treated with $o$-phenylendiamine to produce the corresponding benzodiazepines under mild reaction conditions in high to excellent yields (Table 2).

Table 2. Synthesis of benzodiazepine derivatives in the presence of $\mathrm{Fe}_{3} \mathrm{O}_{4} @$ cellulose.

\begin{tabular}{|c|c|c|c|c|c|}
\hline Entry & Product & Time $(\min )$ & Yield $^{\mathrm{a}}(\%)$ & $\begin{array}{c}\mathrm{Mp}\left({ }^{\circ} \mathrm{C}\right) \\
\text { Observed }\end{array}$ & $\begin{array}{l}\mathrm{Mp}\left({ }^{\circ} \mathrm{C}\right) \\
\text { Reported }\end{array}$ \\
\hline 1 & & 45 & 90 & $132-135$ & $133-134$ [17] \\
\hline 2 & & 25 & 96 & 136-139 & $135-137$ [18] \\
\hline 3 & & 50 & 95 & $133-135$ & $133-134$ [19] \\
\hline 4 & & 70 & 89 & $120-122$ & $122-124[20]$ \\
\hline 5 & & 65 & 97 & $115-117$ & $112-114$ [21] \\
\hline 6 & & 75 & 92 & 99 & $96-98$ [22] \\
\hline
\end{tabular}




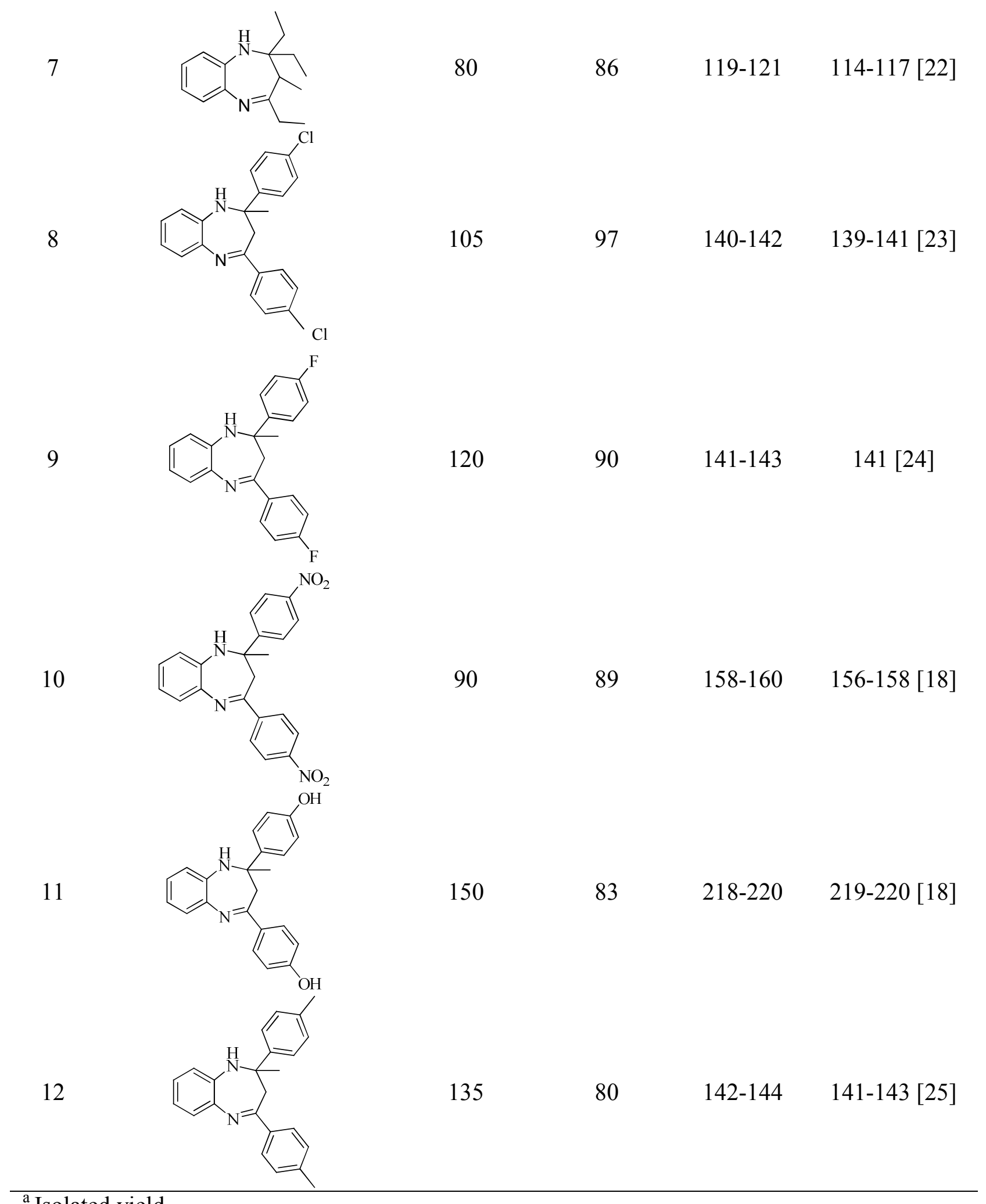

${ }^{\mathrm{a}}$ Isolated yield. 


\section{Characterization}

The nanocomposite films containing $\mathrm{Fe}_{3} \mathrm{O}_{4}$ nanoparticles were prepared by in situ synthesis. The morphology of the nanocomposite films was shown in scheme 1, displayed homogeneous mesoporous structure. This unique structure was due to the phase separation of the cellulose solution during the regenerating process, where the solvent-rich regions contribute to the pore formation. Therefore, it was plausible that the nanocomposite films at wet state had mesoporous structure; it could act as nanoreacting sites where inorganic nanoparticles could be synthesized in situ. Figure $1 \mathrm{~b}$ shows the SEM image of the $\mathrm{Fe}_{3} \mathrm{O}_{4}$ composite film, and energy dispersive spectrum (EDS) from SEM indicated that there were only $\mathrm{C}, \mathrm{O}$ and Fe elements in the composite film, suggesting that the iron oxide has been synthesized in the cellulose films. When the cellulose films were immersed into $\mathrm{FeCl}_{3}$ solution, $\mathrm{Fe}^{3+}$ could be readily impregnated into the cellulose films through the pores. The incorporated $\mathrm{Fe}^{3+}$ ions could be bound to cellulose macromolecules via electrostatic interaction, because the electron rich oxygen atoms of polar hydroxyl of cellulose are expected to interact with electropositive transition metal cations.

\section{Conclusions}

In summary, we have demonstrated a simple method for the synthesis of benzodiazepine using $\mathrm{Fe}_{3} \mathrm{O}_{4} @$ cellulose as an eco-friendly, inexpensive and efficient nanocatalyst. Short reaction times, high yields, scale-up, clean process, simple methodology, easy work-up, and green conditions are the advantages of this protocol. The solid supported nanocatalyst could be recycled and reused without significant loss of its catalytic activity. 


\section{Acknowledgements}

The authors gratefully acknowledge the partial support from the Research Council of the Iran University of Science and Technology.

\section{References}

[1] Brown R. M.; Saxena I. M. Cellulose: Molecular and Structural Biology: Selected Articles on The Synthesis, Stracture and Application of Cellulose; Springer: Netherlands, 2007.

[2] Habibi, Y.; Lucia, L. A.; Rojas, O. J. Chem. Rev. 2010, 110, 3479.

[3] Molvinger, K.; Quignard, F.; Brunel, D.; Boissiere, M. J. M. Chem. Matter. 2004, 16, 3367.

[4] Chakraborty, S.; Shah, N. H.; Fishbein, J. C.; Hosmane, R. S. Bioorg. Med. Chem. Lett. 2011, 21, 756 .

[5] Antonow, D.; Thurston, D. E. Chem. Rev. 2011, 111, 2815.

[6] Stahlofen, P.; Ried, W. Chem. Ber. 1957, 90, 815.

[7] Ried. W.; Torinus, E. Chem. Ber. 1959, 92, 2902.

[8] Jarikote, D. V.; Siddiqui, S. A.; Rajgopal, R.; Thoma, D.; Lahoti, R. J.; Srinivasan, K. V. Tetraheron Lett. 2003, 44, 1835.

[9] Sucheta, K.; Vital Rao, B. Indian J. Chem. Sect. B: Org Chem. Incl. Med. Chem. 2005, $44,2152$.

[10] Ganai, B. A.; Kumar, S.; Andotra, C. S.; Kapoor, K. K. Synth. Commun. 2006, 36, 803. 
[11] Weissenfels, M.; Kache, R.; Krauter, W. J. Prakt. Chem. 1967, 35, 166.

[12] Amey, R. L.; Heindel, N. D. Org. Prep. Proced. Int. 1976, 8, 306.

[13] Dai-11, J.; Tae-wonchoi, C.; Yun-Young, K.; In-Shik, K.; You-Mi, P.; Yong-Gyun, L.; Doo-Hee, J. Synth. Commun. 1999, 29, 1941.

[14] Zhong, W.; Zhanga, Y.; Chenc, X. Tetrahedron Lett. 2001, 42, 73.

[15] Curini, M.; Epifano, F.; Marcotullio, M. C.; Rosati, O. Tetrahedron Lett. 2001, 42, 3193.

[16] Heravi, M. M.; Derikvand, F.; Ranjbar, L.; Bamoharram, F. F. J. Mol. Catal. A: Chem. 2007, 261, 156.

[17] More, U. B.; Kharat, R. S.; Mahulikar, P. P. Asian J. Chem. 2011, 23, 4311.

[18] Vijayasankar, A. V.; Deepa, S.; Venugopal, B. R.; Nagaraju, N. Chin. J. Catal. 2010, 31, 1321.

[19] Sandhar, A.; Singh, R. K. Asian J. Chem. 2012, 24, 5643.

[20] Suresh; S. A.; Sandhu, J. S. Synth. Commun. 2008, 38, 3193.

[21] Yadav, J. S.; Reddy, B. V. S.; Praveenkumar, S.; Nagaiah, K. Synthesis 2005, 480.

[22] Zhong, W.; Zhang, Y.; Chen, X. J. Chem. Res. (S) 2000, 11, 532.

[23] Maiti, G.; Kayal, U.; Karmakar, R.; Bhattacharya, R. N. Tetrahedron Lett. 2012, 53, 1460.

[24] Qian, J.; Liu, Y.; Cui, J.; Xu, Z. J. Org. Chem. 2012, 77, 4484.

[25] Chen, W.-Y.; Lu, J. Synlett 2005, 1337.

[26] (a) Maleki, A. Tetrahedron 2012, 68, 7827; (b) Maleki, A. Tetrahedron Lett. 2013, 54, 2055. 